\title{
Varenicline treatment for smoking cessation in high risk patients: a budget impact analysis
}

\author{
Federico Spandonaro ${ }^{1,2}$, Letizia Mancusi ${ }^{2}$, Barbara Polistena ${ }^{1,2}$ \\ ${ }^{1}$ University of Rome Tor Vergata, Rome, Italy \\ ${ }^{2}$ C.R.E.A. Sanità - Consortium for Applied Health Economic Research, Rome, Italy
}

\begin{abstract}
INTRODUCTION: The promotion of smoking cessation is a worldwide Public Health priority. OBJECTIVE: To estimate the budget impact on the Italian National Health Service (NHS) of the access to reimbursement of varenicline for the treatment of high risk patients with bronchopulmonary, diabetic and cardiovascular diseases. METHODS: A closed-group Markov model was developed in order to compare the costs incurred by the NHS to promote smoking cessation with cessation-related savings, using an alternative scenario in which aids to cessation are not reimbursed by the NHS. The analysis was conducted over a 5-year time horizon, in the perspective of the Italian NHS. Efficacy was expressed in terms of smoke abstinence for at least one year, and data was derived from clinical trials; the savings associated with smoking cessation were derived from cost-of-illness studies.

RESULTS: The results show how costs would concentrate in the first year: they are estimated at $€ 200.6$ million, of which $€ 162.4$ million for drug therapy and $€ 38.2$ million for counseling. Average annual savings over the first five years are estimated at $€ 77.7$ million, with a cumulative net impact at 5 years of $€-188.0$ million (cost-saving). The analysis appears to be robust: sensitivity analyses show that the covering of initial costs occurs in any case between the third and fourth year, and that the treatment remains cost-saving at 5 years.

CONCLUSIONS: The financial impact on the Italian NHS of the reimbursement of varenicline for the treatment of high risk smoking population would be a sustainable healthcare policy, resulting in cost savings starting from the fourth year.
\end{abstract}

\section{Keywords}

Varenicline; Budget Impact; Smoking cessation

\section{INTRODUCTION}

The promotion of smoking cessation is a worldwide Public Health priority, since tobacco addiction represents one of the major risk factors in the development of neoplastic, cardiovascular and respiratory diseases.

According to World Health Organization (WHO) data, tobacco smoke kills 5 million people per year worldwide and is responsible for 1 death out of 10 among the adult population. The WHO also estimates that about half of regular smokers are destined to die prematurely, due to tobacco consumption [1], and similar values also emerge from studies conducted on individual Countries [2].

Tobacco consumption increases the risk of cardiovascular (CVD) [3,4] and bronchopulmonary diseases (COPD - chronic obstructive pulmonary disease) $[5,6]$, as well as being the main cause of some types of cancer. It is also a risk factor for several chronic conditions, including type 2 diabetes [7].
The pathological effects of smoking are related to the duration of exposure (number of years) and its intensity (average number of cigarettes per day) [8]. It is estimated that for smokers the risk of developing bronchopulmonary pathologies ranges from 20 to $50 \%$, depending on exposure and intensity, compared to a $10-15 \%$ risk - thus limited, although not equal to zero - in non-smokers [6]. In addition, for this disease category, it has been shown that smoking accelerates the progression of the disease $[9,10]$.

Giving up this addiction has beneficial effects on the health of patients. The results of a literature review show that - in coronary patients - quitting smoking reduces the risk of mortality by $36 \%$ and the risk of infarction by $32 \%$ [11].

Keeping the smoking phenomenon under control is a priority also because of its economic consequences. A European Commission study shows that, in 2000 , direct health
Corresponding author Federico Spandonaro federico.spandonaro@uniroma2.it

\section{Disclosure}

This study was funded by an unconditional grant from Pfizer Italia. 
costs for the damage caused by smoking affected the GDP of the various Countries by 1.04 to $1.39 \%$ [12].

In Italy, as in most Western Countries, several tobacco control measures have been introduced in the last decades, both of the educational (e.g. campaigns for the promotion of good lifestyles) and deterring type (e.g. ban on smoking in public places). These policies yielded significant results: according to ISTAT data, from 2001 to 2015 the proportion of smokers dropped from $23.7 \%$ to $19.6 \%$, with a significantly higher decrease (from $31 \%$ to $24.6 \%$ ) among men - who started from a very high prevalence - compared to women (from $16.9 \%$ to $15.0 \%$ ).

The prevalence of smokers remains, however, still too high: according to OECD data, Italy is - among the EU15 Countries - sixth in terms of amount of smokers, after Greece, Austria, Spain, France and Germany [13]. In addition to the enhancement of the aforementioned approaches, pharmacological treatments are available to help the smoking cessation.

The aim of this analysis is to estimate the budget impact on the Italian NHS resulting from the access to reimbursement of varenicline for the treatment of patients with COPD, diabetes and CVD.

\section{MATERIALS AND METHODS}

Varenicline is a partial agonist of the a $4 \mathrm{~b} 2$ receptors, and exerts a strong antagonistic action against nicotine at the level of the same receptors, as well as a partial agonist action, that occurs with a lower release of dopamine compared to nicotine.

Specifically, by acting nicotine-like at cerebral level, it is able to reduce the desire for cigarettes, thus helping some patients quit smoking.

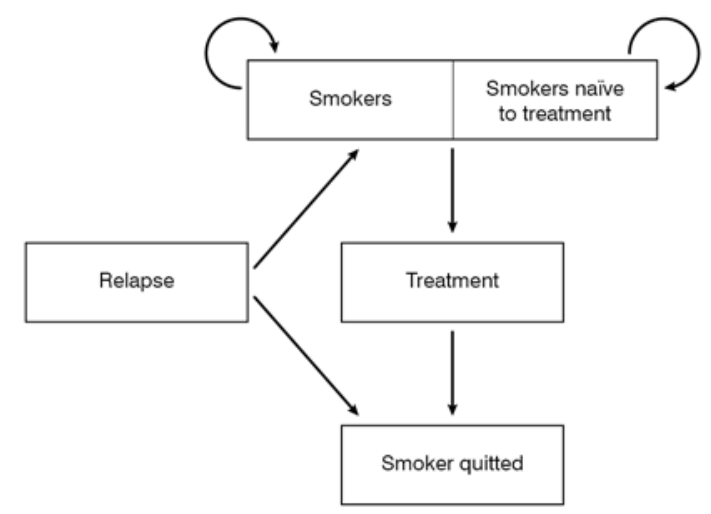

Figure 1. Markov mode/ structure

\section{The model}

The model compares the costs incurred to promote smoking cessation and the cessation-related savings, using an alternative scenario in which aids to cessation are not reimbursed by the NHS.

The analysis was conducted over a 5-year time horizon, in the perspective of the Italian NHS. Given the short time horizon considered, savings and costs were not discounted. The model has a closed-group Markovian structure; in other words, the smokers cohort is considered and followed over time, without considering new entrances in the smoker status (Figure 1).

The Markov model includes the smoker status (naïve, and due to ineffectiveness of the treatment or to relapse) and the non-smoker status. The model does not include the estimate of the mortality rate of smokers since, over the 5-year time horizon adopted, the number of deaths would be extremely low and therefore would not substantially affect the results of the model.

\section{Treatment eligible population}

The prevalent Italian population with COPD, diabetes, and CVD - who stated its intention to stop smoking - was considered. This population was offered both a pharmacological support, with varenicline, and a counseling service.

For the estimate of prevalent cases, the data of the National Statistics Institute (ISTAT) - collected during the Statistical Survey on the Health Conditions of the Population and the Resort to Health Services were used [14]. The survey reference period are the 12 months from July 2012 to June 2013.

The sampling design has a general structure that resembles that of the sampling patterns of most household surveys, that is, a multistage, district-family design, with stratification of the Districts. In the reference period, the sample involved 60,368 families, for a total number of subjects equal to 119,073 . As for tobacco addiction, the survey was conducted on the population starting from 14 years of age, which in 2013 amounted to 52,352,094 people [15].

People who declare to be suffering from COPD or emphysema are just over 2,225,000, of whom over 544,611 are smokers (Table I). As for diabetes, over 3.4 million people stated to be suffering from it, with a prevalence of 65.1 out of 1,000 inhabitants. Of these, 483,223 are smokers (Table I). Finally, as for CVD, namely AMI (acute myocardial infarction), angina pectoris and stroke, there are a total of 2,682,964 individuals, of whom 333,119 are smokers. 
The population eligible for treatment was estimated using the evidence available on the proportion of those who are planning to quit smoking with the help of the drug, net of those who would stop in any case [7]. Patients eligible for pharmacological treatment would therefore be 217,572 with COPD, 154,535 with diabetes and 106,531 with CVD (Table I).

\section{Treatment efficacy}

Regarding the efficacy of the treatment (Table II), the values adopted in this analysis are derived from the literature [7]. In particular, efficacy at week 52 of treatment was assumed to be $18.6 \%$ for COPD, $20.0 \%$ for diabetes and 19.2\% for CVD [7]. The metaanalysis carried out by Hoogendoorn et al. [16] showed that the 12-months smoking abstinence rate in patients with COPD who followed the usual care, defined as the absence of any type of smoking cessation intervention, was negligible (about 1\%). The rate of relapses was assumed to be $3 \%$ per year [7] for the entire eligible population considered.

\section{Costs}

The price of the drug used for the calculation is $€ 339.31$, equal to the cost (retail price in class A) of 12 weeks of treatment, as indicated in the SPC [17]: one $0.5 \mathrm{mg}$ tablet once daily for 3 days, then one $0.5 \mathrm{mg}$ tablet twice daily for 4 days and finally one $1.0 \mathrm{mg}$ tablet twice daily for the remaining 11 weeks of treatment (Table III).

As for the counseling service, 4 visits with a psychologist were assumed, for a total amount of $€ 79.84$ (unit cost of the visit equal to $€ 19.96$, as specified by the Italian National Tariff [18]) (Table III).

As for the estimate of the savings resulting from the cessations, this was done separately, for each disease branch ${ }^{1}$.

The average annual cost per COPD patient was assumed to be $€ 2,723.7$ [19]; the estimate for the smoking and non-smoking population was carried out by adopting the savings ratio collected by Sicras-Mainar [6] from a cohort of Spanish patients with COPD specifically treated to promote smoking cessation, which highlighted a cost of $€ 3.775,4$ per smoking patient and $€ 2,382.4$ per no longer smoking patient, with an average annual saving per capita resulting from the cessation of $€ 1,393.0$.

Through a similar procedure, patients with diabetes are assumed to have a mean annual cost per patient of $€ 2,898.0$ [20].

Reduction in costs is related to the reduction in the number of visits and days of hospitalization between smoking and no longer smoking patients

\begin{tabular}{lccc}
\hline & $\begin{array}{c}\text { COPD/ } \\
\text { emphysema }\end{array}$ & Diabetes & $\begin{array}{c}\text { AMI, angina, } \\
\text { stroke }\end{array}$ \\
\hline Total & $2,225,039$ & $3,406,477$ & $2,682,964$ \\
Non-smokers & $1,680,428$ & $2,923,254$ & $2,349,845$ \\
Smokers & 24.48 & 14.19 & \\
• \% & 544,611 & 483,223 & 12.42 \\
• n. & & 333,119 \\
Smokers willing to quit [7] & 31.98 & \\
• \% & 39.95 & 154,535 & 31.98 \\
• n. & 217,572 & 106,531 \\
\hline
\end{tabular}

Table I. Smoker population > 14 years with COPD/emphysema, diabetes, or cardiovascular disease and patients eligible for pharmacological treatment $\mathrm{AMI}=$ acute myocardial infarction; $\mathrm{COPD}=$ chronic obstructive pulmonary disease

\begin{tabular}{cccc}
\hline \multicolumn{1}{c}{ Input } & COPD & Diabets & CVD \\
\hline Efficacy at week 52 (\%) & 18.60 & 20.00 & 19.20 \\
Rate of relapses (\%) & 3.00 & 3.00 & 3.00 \\
\hline
\end{tabular}

Table II. Treatment efficacy [7]

$\mathrm{COPD}=$ chronic obstructive pulmonary disease; $\mathrm{CVD}=$ cardiovascular disease

\begin{tabular}{lcc}
\hline \multicolumn{1}{c}{ Cost item } & Input & Source \\
\hline Drug cost $(€)$ & 339.31 & $\begin{array}{c}\text { Retail price in class A of } \\
12 \text { weeks of treatment }\end{array}$ \\
Psychological visits & 19.96 & {$[18]$} \\
- Unit cost $(€)$ & 4.00 & Assumption \\
- $n$. & 79.84 & - \\
- Total cost $(€)$ & 419.15 & - \\
Total cost of therapy $(€)$ & & - \\
\hline
\end{tabular}

Table III. Costs of therapy

Based on the findings of Sicras-Mainar [21] in a cohort of Spanish diabetic patients, a cost of $€ 3,637.6$ and $€ 2,864$.0 is estimated for the smoking and the no longer smoking population, respectively, with an annual saving per cessation of $€$ 774.0.

The annual cost per CVD patient was estimated based on the studies conducted by Fattore et al. [22] on stroke and Roggeri et al. [23] on myocardial infarction and angina, which report values of $€ 11,747.0$ and $€$ 11,464.0, respectively. An average cost was adopted, weighted on the number of the sampled populations analyzed.

Using the findings of Sicras-Mainar [24] in a cohort of Spanish patients with CVD (angina pectoris, AMI, stroke and transient ischemic attack), an average annual cost of $€ 12,511.0$ and $€ 11,313.5$ is estimated, for smokers and ex-smokers, respectively, with an annual saving per cessation of $€ 1,197.5$. 


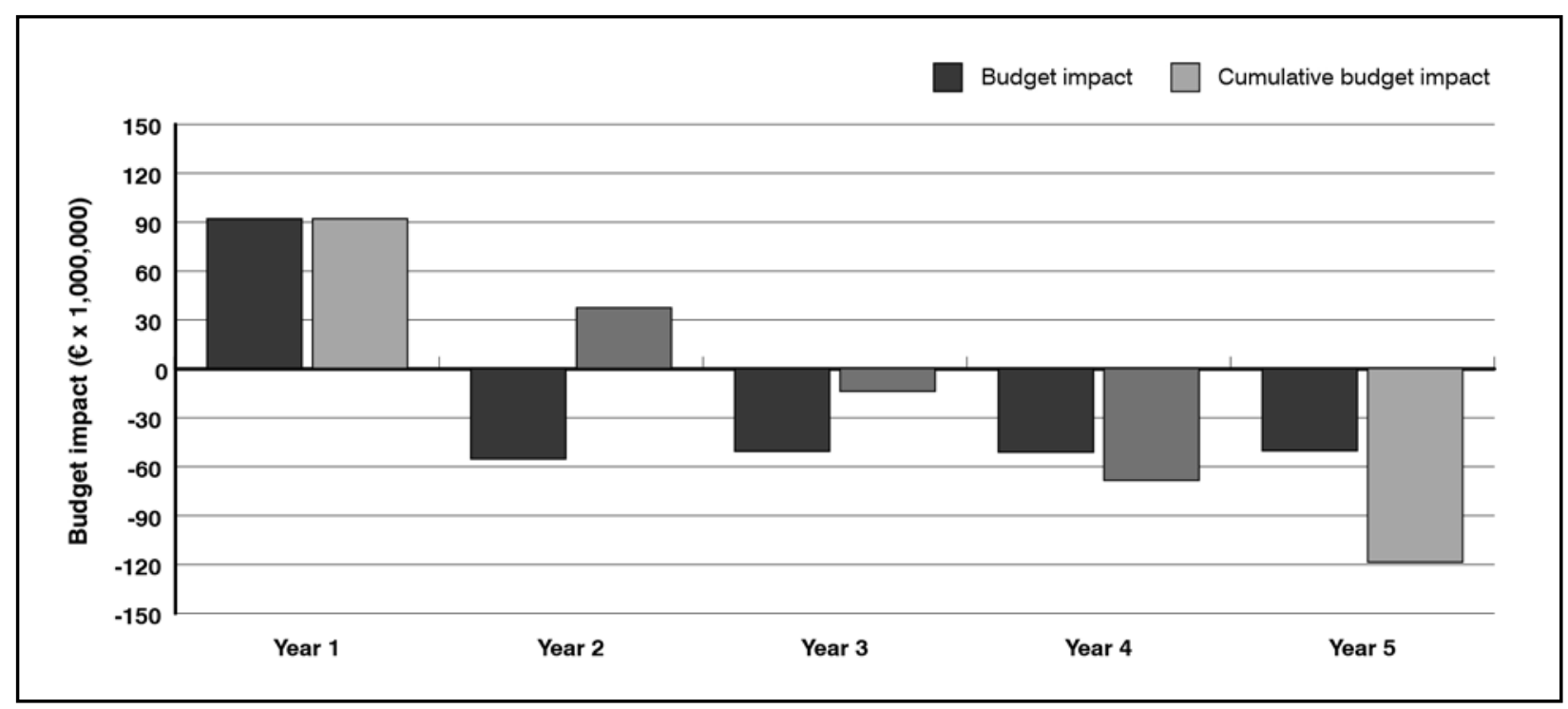

Figure 2. Budget impact of varenicline in smokers with COPD

\begin{tabular}{lccccc}
\hline & Year 1 & Year 2 & Year 3 & Year 4 & Year 5 \\
\hline Additional costs $(€)$ & $91,195,343$ & - & - & - & - \\
Savings $(€)$ & 0 & $-54,681,985$ & $-53,041,525$ & $-51,450,279$ & $-49,906,771$ \\
Budget impact $(€)$ & $91,195,343$ & $-54,681,985$ & $-53,041,525$ & $-51,450,279$ & $-49,906,771$ \\
Cumulative budget impact $(€)$ & $91,195,343$ & $36,513,359$ & $-16,528,167$ & $-67,978,446$ & $-117,885,217$ \\
\hline
\end{tabular}

Table IV. Budget impact of varenicline in smokers with COPD

\section{Sensitivity analysis}

In order to evaluate the impact of the uncertainty of the input parameters on the results obtained, a univariate sensitivity analysis was conducted, in which a variation of relapses of $\pm 2 \%$, a change in unit savings of \pm $10 \%$, and a variation of the population treated of $\pm 10 \%$ were assumed.

\section{RESULTS}

Italian COPD patients who smoke but are also willing to quit are 217,572; should the reimbursability of varenicline be recognized for those who are planning to stop smoking with the aid of the drug, net of those who would stop in any case, the cost for the NHS would be $€ 91.2$ million, concentrated in the

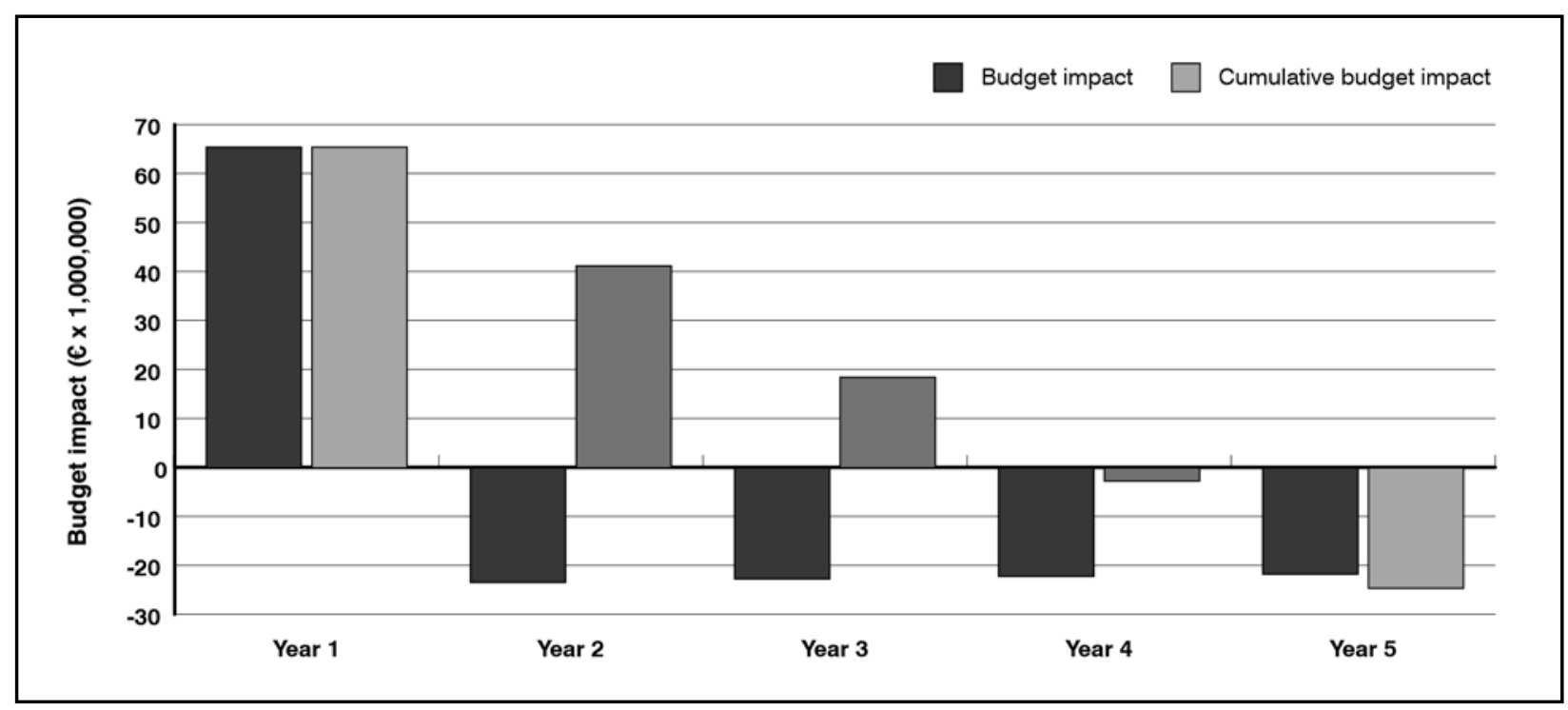

Figure 3. Budget impact of varenicline in smokers with diabetes 


\begin{tabular}{lccccc}
\hline & Year 1 & Year 2 & Year 3 & Year 4 & Year 5 \\
\hline Additional costs $(€)$ & $64,773,226$ & - & - & - & - \\
Savings $(€)$ & 0 & $-23,193,097$ & $-22,497,304$ & $-21,822,385$ & $-21,167,714$ \\
Budget impact $(€)$ & $64,773,226$ & $-23,193,097$ & $-22,497,304$ & $-21,822,385$ & $-21,167,714$ \\
Cumulative budget impact $(€)$ & $64,773,226$ & $41,580,129$ & $19,082,824$ & $-2,739,561$ & $-23,907,275$ \\
\hline
\end{tabular}

Table V. Budget impact of varenicline in smokers with diabetes

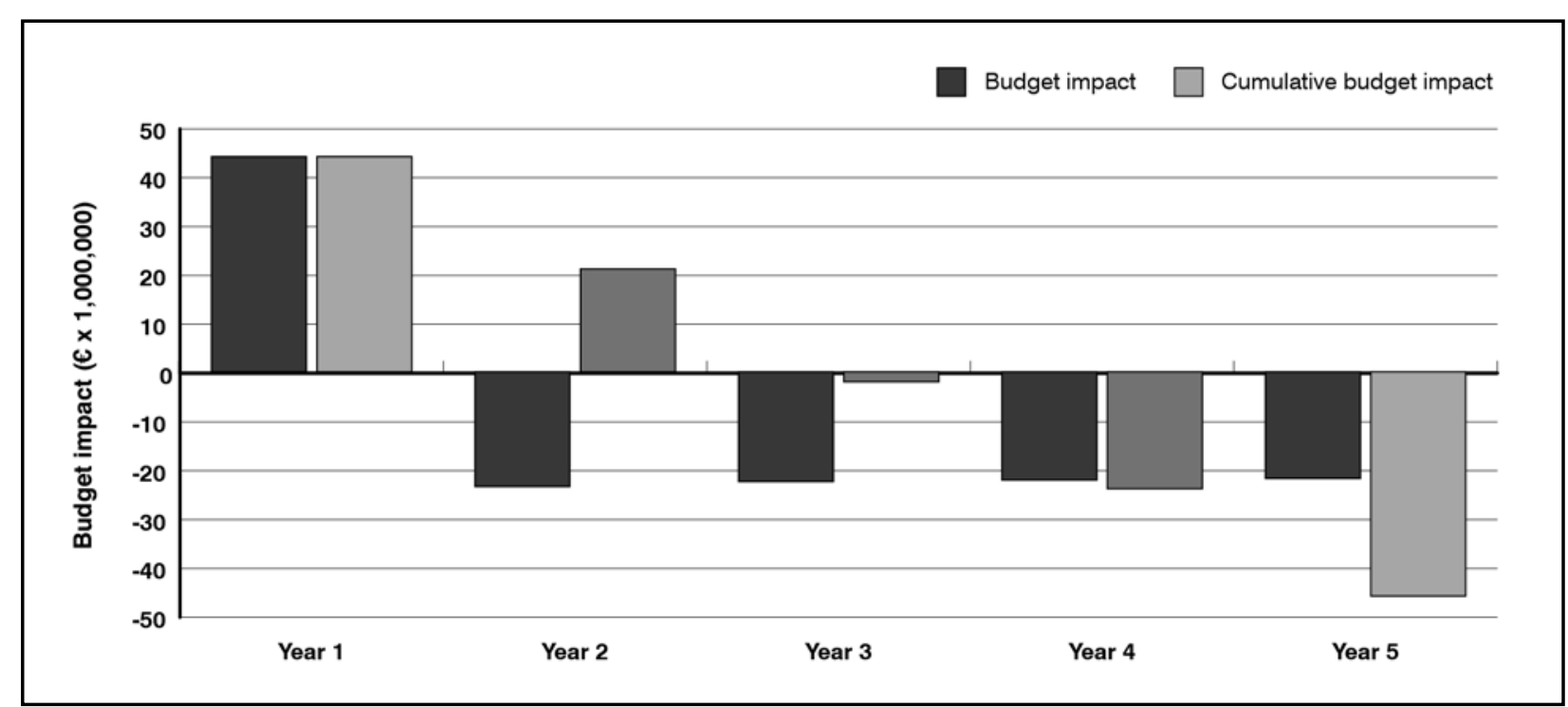

Figure 4. Budget impact of varenicline in smokers with CVD

\begin{tabular}{lccccc}
\hline & Year 1 & Year 2 & Year 3 & Year 4 & Year 5 \\
\hline Additional costs $(€)$ & $44,652,660$ & - & - & - & - \\
Savings $(€)$ & 0 & $-23,758,305$ & $-23,045,555$ & $-22,354,189$ & $-21,683,563$ \\
Budget impact $(€)$ & $44,652,660$ & $-23,758,305$ & $-23,045,555$ & $-22,354,189$ & $-21,683,563$ \\
Cumulative budget impact $(€)$ & $44,652,660$ & $20,894,355$ & $-2,151,200$ & $-24,505,389$ & $-46,188,952$ \\
\hline
\end{tabular}

Table VI. Budget impact of varenicline in smokers with CVD

first year (of which $€ 73.8$ million for the drug and $€ 17.4$ million for counseling); the cumulative savings in the first five years would amount to $€ 209.1$ million, with a savings of $€ 117.9$ million for the NHS (Figure 2). Treatment of COPD patients becomes costsaving starting from the third year (Table IV and Figure 2).

Italian diabetic patients who smoke but are also willing to quit are 154,535; should the reimbursability of varenicline be recognized, the cost for the NHS would be $€ 64.8$ million, all concentrated in the first year (of which $€$ 52.4 million for the drug and $€ 12.3$ million for counseling); the cumulative savings achievable in the first five years would amount to $€$ 88.7 million, with a savings of $€ 23.9$ million for the NHS. Treatment of patients with diabetes becomes cost-saving starting from the fourth year (Table V and Figure 3).
Italian patients with CVD who smoke but are also willing to quit are 106,531; should the reimbursability of varenicline be recognized, the cost for the NHS would be $€ 44.6$ million, concentrated in the first year (of which $€ 36.1$ million for pharmacotherapy and $€ 8.5$ for counseling); the cumulative savings in the first five years would amount to $€ 90.8$ million, with a saving of $€ 46.2$ million for the NHS. Treatment of patients with CVD becomes cost-saving starting from the third year (Table VI and Figure 4).

\section{Sensitivity analysis}

The reimbursement of varenicline remains constantly cost-saving starting from the third year of treatment, except where there is a $10 \%$ reduction in unit savings or a $10 \%$ increase in the population treated: in these cases the treatment becomes however cost- 


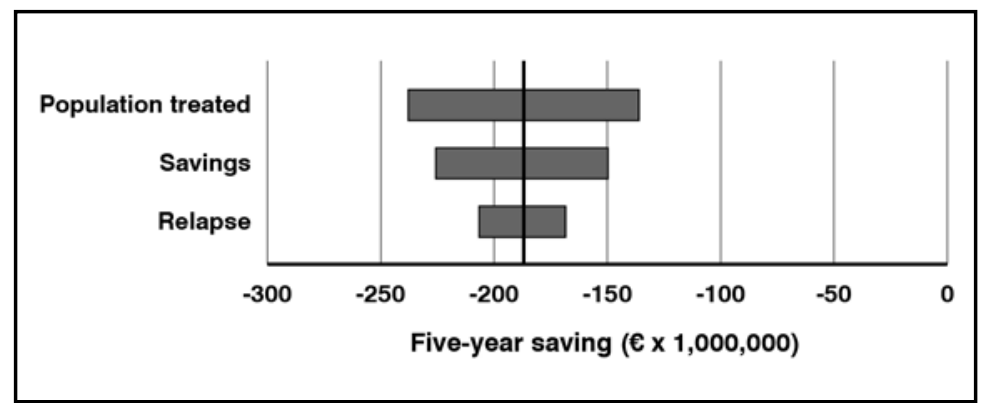

Figure 5. Results of the sensitivity analysis: the tornado diagram

saving starting from the fourth year. The tornado diagram (Figure 5) reports the five-year savings achieved in the various simulations.

\section{DISCUSSION}

Studies on the efficacy and cost-effectiveness of the pharmacological smoking cessation therapy, often associated with a motivational support, are relatively recent and show an evolution in terms of achievable goals.

The first studies, in fact, were carried out in order to evaluate the effectiveness of the pharmacological treatment: Cahill et al. [25], through a literature review, show the high rate of success (smoking abstinence) in healthy subjects undergoing varenicline therapy, compared with placebo and bupropion. Similarly, other studies $[26,27]$ show a $44 \%$ cessation rate after 12 weeks of therapy, versus lower average values $(17.6 \%)$ for placebo-treated patients.

Efficacy analyses on populations with conditions for which smoking is an aggravating factor were subsequently published: a controlled study [28] - conducted on a sample of 714 smokers with CVD from 15 different countries - evaluated the rate of success of varenicline (administered for 12 weeks) versus placebo, highlighting an average 12 -week abstinence rate of $54.1 \%$ among the patients treated, versus $18.1 \%$ among the controls; the persistence of abstinence at one year remains higher in the varenicline group (19.2\%) versus controls $(7.2 \%)$.

The pharmacoeconomic aspect was examined in depth through an analysis carried out in four European Countries (Belgium, Spain, Portugal and Italy) by Wilson et al. [3]: based on the evidence highlighted by Rigotti et al. [28], the cost per QALY gained with the use of varenicline is estimated at $€ 6,120$ for Belgium, $€ 5,151$ for Spain, $€ 5,357$ for Portugal, and $€ 5,433$ for Italy.

A study with a similar structure to those previously mentioned, conducted in patients with chronic obstructive pulmonary disease (COPD) [29] in Spain, Germany, United
Kingdom, Greece and Italy, shows a cost per QALY gained at 52 weeks ranging from a minimum of $€ 4,478$ for UK, up to a maximum of $€ 10,167$ for Italy.

The 10-year extrapolation shows a decrease in the Incremental Cost-Effectiveness Ratio (ICER): in the short term (4-5 years) varenicline is cost-effective adopting a willingness to pay (WTP) greater than $€ 30,000$, while with a longer time horizon it becomes costeffective with a WTP greater than $€ 20,000$. A retrospective, multicentre, 24-month study [30] - conducted in a primary care setting in Spain on smokers followed by their GP considered the varenicline therapy, with or without psychological support, and revealed that psychological support increases the adherence to therapy, and therefore the success in quitting smoking.

Various studies have shown that, increasing the adherence to treatment, the public funding of antismoking drugs may be an essential condition for the effectiveness of the treatment itself [31,32].

The Budget Impact deriving from the access to reimbursement of smoking cessation drugs, and in particular varenicline, was repeatedly analyzed: Taylor et al. [33] demonstrated the economic benefits deriving from the reimbursement of varenicline in the perspective of the UK NHS; in Spain Jiménez-Ruiz et al. [5] came to the same conclusions for COPD patients over a 5-year time horizon.

Cedillo et al. [7] - considering as target population smokers with COPD, t2-DM or CVD, who represent a high-risk population both in terms of health and healthcare resources - estimate that varenicline reimbursement would be cost-saving from the third year.

This study, adopting a perspective similar to that of Cedillo et al. [7], evaluates the budget impacts of the access to reimbursement of varenicline, in the perspective of the Italian NHS.

Overall, a burden of $€ 200.6$ million is estimated for the first year - of which $€ 162.4$ million for drug therapy and $€ 38.2$ million for counseling - which would be offset in the third year; from the fourth year, the treatment is cost-saving, with a 5-year savings of $€ 188.0$ million.

It was assumed that all eligible patients were treated in the first year, which is an apparently unlikely supposition, because the burdens will certainly be divided over several years: for the purposes of the budget impact assessment, it was decided to provide the most extreme data, avoiding the introduction of arbitrary hypotheses on the uptake of patients. Based on the aforementioned assumptions and data, the financial impact (all concentrat- 
ed in the first year) is less than $1.85 \%$ of the Class A public pharmaceutical expenditure [34], and less than $0.002 \%$ of the national public health expenditure, without even considering any wholesale discounts.

\section{CONCLUSIONS}

The financial impact on the Italian NHS of the reimbursement of varenicline for the high-risk smoking population willing to stop would be a sustainable healthcare policy, resulting cost-savings from the fourth year. In particular, it should be noted that the costs, that was estimated at $€ 200.6$ million, would be concentrated in the first year. Average annual savings over the first five years are estimated at $€ 77.7$ million, with a five-year savings of $€ 188.0$ million.

Conclusions appear to be robust: sensitivity analyses show that the covering of initial costs occurs in any case between the third and fourth year, and that the treatment remains in any case cost-saving at 5 years.

The perspective used is that of the Italian NHS, and therefore it does not take into account the indirect costs (benefits for society deriving from lower productivity losses) and the out-of-pocket direct costs incurred by families: the analysis can therefore be considered conservative.

\section{Conflict of interests}

FS reports financial relationships with $3 \mathrm{M}$, Abbott, Bayer, Biogen Idec, Biomarine, BMS, BoehringerIngelheim, Celgene, Daiichy Sankyo, Edwards, Eli Lilly, Genzyme, GlaxoSmithKline, Janssen Cilag, Johnson \& Johnson, Lundbeck, Medac, MSD Italia, Medtronic, Nestlè Health Science, Novartis, Novo Nordisk, Obi, Otsuka, Pfizer, Roche, Sanofi, Sanofi Pasteur MSD, Servier, Sigma Tau, Stroder, Takeda, Teva, outside the present work.

BP reports financial relationships with Abbott,

Bayer, Daiichy Sankyo, Edwards, Eli Lilly, Genzyme, Lundbeck, Medac, Otsuka, Pfizer, Roche, Servier,

outside the present work.

RLM has nothing to disclose.

\section{BIBLIOGRAFIA}

1. WHO - World Health Organization. Geneva. Health Topics - Tobacco. Available at http://www.who.int/topics/ tobacco/en/

2. Doll R, Peto R, Wheatley K, et al. Mortality in relation to smoking: 40 years' observations on male British doctors. BMJ 1994; 309: 901-11

3. Wilson K, Hettle R, Marbaix S, et al. An economic evaluation based on a randomized placebo-controlled trial of varenicline in smokers with cardiovascular disease: results for Belgium, Spain, Portugal, and Italy. Eur J Prev Cardiol 2012; 19: 1173-83; https://doi.org/10.1177/1741826711420345

4. CDCP - Centers for Disease Control and Prevention, US Department of Health and Human Services. The health consequences of smoking: A report of Surgeon General. Washington, DC: US Government Printing Office, 2004

5. Jiménez-Ruiz CA, Solano-Reina S, Signes-Costa J, et al. Budgetary impact analysis on funding smoking cessation drugs in patients with COPD in Spain. Int J Chron Obstruct Pulmon Dis 2015; 10: 2027-36; https://doi.org/10.2147/ COPD.S87597

6. Sicras-Mainar A, Rejas-Gutiérrez J, Navarro-Artieda R, et a. The Effect of Quitting Smoking on Costs and Healthcare Utilization in Patients with Chronic Obstructive Pulmonary Disease: A Comparison of Current Smokers Versus Ex-Smokers in Routine Clinical Practice. Lung 2014; 192: 505-18; https://doi.org/10.1007/s00408-014-9592-7

7. Cedillo S, Sicras-Mainar A, Jiménez-Ruiz CA, et al. Budgetary Impact Analysis of Reimbursement Varenicline for the Smoking-Cessation Treatment in Patients with Cardiovascular Diseases, Chronic Obstructive Pulmonary Disease or Type-2 Diabetes Mellitus: A National Health System Perspective. Eur Addict Res 2017; 23: 7-18; https:// doi.org/10.1159/000449098

8. McGorrian C, Yusuf S, Islam S, et al. Estimating modifiable coronary heart disease risk in multiple regions of the world: the INTERHEART modifiable risk score. Eur Heart J 2011; 32: 581-9; https://doi.org/10.1093/eurheartj/ ehq448

9. Anthonisen NR, Connett JE, Kiley JP, et al. Effects of smoking intervention and the use of an inhaled anticholinergic bronchodilator on the rate of decline of FEV1. The Lung Health Study. JAMA 1994; 272: 1497-505

10. Scanlon PD, Connett JE, Waller LA, et al. Smoking cessation and lung function in mild-to-moderate chronic obstructive pulmonary disease. The Lung Health Study. Am J Respir Crit Care Med 2000; 161: 381-90

11. Critchley J, Capewell S. Smoking cessation for the secondary prevention of coronary heart disease. Cochrane Database Syst Rev 2004; (1): CD003041

12. European Commission, 2004,: Directorate-General for Health and Consumer Protection, The ASPECT Consortium. Tobacco or health in the European Union: Past, present and future. 2004. http://ec.europa.eu/health/ph_determinants/ life_style/Tobacco/Documents/tobacco_exs_en.pdf 
13. Organisation for Economic Co-operation and Development (OECD). Available at https://data.oecd.org/

14. ISTAT - Statistical Survey on the Health Conditions of the Population and the Resort to Health Services. Available at https://www.istat.it/it/archivio/5471

15. ISTAT - Aspects of daily life. Year 2013. Available at https://www.istat.it/it/archivio/129916

16. Hoogendoorn M, Feenstra TL, Hoogenveen RT, et al. Long-term effectiveness and cost-effectiveness of smoking cessation interventions in patients with COPD. Thorax 2010; 65: 711-8; https://doi.org/10.1136/thx.2009.131631

17. Champix - Summary of Product Characteristics. Available at http://www.ema.europa.eu/docs/it_IT/document_library/EPAR___Product_Information/human/000699/WC500025251.pdf

18. Nomenclatore tariffario dell'assistenza specialistica ambulatoriale. Tariffa Unica Convenzionale. Edizione 2013

19. Dal Negro RW, Tognella S, Tosatto B, et al. Costs of chronic obstructive pulmonary disease (COPD) in Italy: The SIRIO study (Social Impact of Respiratory Integrated Outcomes). Respir Med 2008; 102: 92-101

20. Osservatorio ARNO Diabete Il profilo assistenziale della popolazione con diabete, Rapporto 2015 Volume XXIII - Collana “Rapporti ARNO”, http://www.siditalia.it/images/Documenti/NEWS/Rapporto_Arno_Diabete_2015.pdf

21. Sicras-Mainar A, Rejas-Gutiérrez J, Navarro-Artieda R, et al. Effect of Smoking Status on Healthcare Costs and Resource Utilization in Patient with Type 2 Diabetes in Routine Clinical Practice: A Retrospective Nested CaseControl Economic Study. Eur Addict Res 2014; 20: 94-104; https://doi.org/10.1159/000355171

22. Fattore G, Torbica A, Susi A, et al. The social and economic burden of stroke survivors in Italy: a prospective, incidence-based, multi-centre cost of illness study. BMC Neurol 2012; 12: 137; https://doi.org/10.1186/1471-2377$12-137$

23. Roggeri D, Roggeri A, Rossi E, et al. Direct healthcare costs and resource consumption after acute coronary syndrome: a real-life analysis of an Italian subpopulation. Eur J Prev Cardiol 2014; 21: 1090-6; https://doi. org/10.1177/2047487313483608

24. Sicras-Mainar A, Díaz-Cerezo S, de Burgoa VS, et al. Cost and clinical consequences of smoking cessation in outpatients after cardiovascular disease: a retrospective cohort study Clinicoecon Outcomes Res 2013; 5: 419-27; https://doi.org/10.2147/CEOR.S43256

25. Cahill K, Stead LF, Lancaster T. Nicotine receptor partial agonists for smoking cessation. Cochrane Database Syst Rev 2008; 3: CD006103; https://doi.org/10.1002/14651858.CD006103.pub3

26. Gonzales D, Jorenby DE, Brandon TH, et al. Immediate versus delayed quitting and rates of relapse among smokers treated successfully with varenicline, bupropion SR or placebo. Addiction 2010; 105: 2002-13; https://doi. org/10.1111/j.1360-0443.2010.03058.x

27. Jorenby D, Hays T, Rigotti N, et al. Efficacy of varenicline, an alpha4beta2 nicotinic acetylcholine receptor partial agonist, vs placebo or sustained-release bupropion for smoking cessation: a randomized controlled trial. JAMA 2006; 296: 56-63; https://doi.org/10.1001/jama.296.1.56

28. Rigotti NA, Pipe AL, Benowitz NL, et al. Efficacy and Safety of Varenicline for Smoking Cessation in Patients With Cardiovascular Disease: A Randomized Trial. Circulation 2010; 121: 221-9; https://doi.org/10.1161/CIRCULATIONAHA.109.869008

29. Lock K, Wilson K, Murphy D, et al. A cost-effectiveness model of smoking cessation based on a randomized controlled trial of varenicline versus placebo in patients with chronic obstructive pulmonary disease. Expert Opin Pharmacother 2011; 12: 2613-26; https://doi.org/10.1517/14656566.2011.628935

30. Pascual FC, Ferrándiz J, Gil Sanchez MC, et al. Two-Year Therapeutic Effectiveness of Varenicline for Smoking Cessation in a Real-World Setting. Subst Use Misuse 2016; 51: 131-40; https://doi.org/10.3109/10826084.2015.1 018547

31. Zhu SH, Anderson CM, Tedeschi GJ, et al. Evidence of real-world effectiveness of a telephone quitline for smokers. N Engl J Med 2002; 347: 1087-93

32. Van Boven J, PharmD, Vemer P. Higher Adherence During Reimbursement of Pharmacological Smoking Cessation Treatments. Nicotine Tob Res 2016; 18: 56-63; https://doi.org/10.1093/ntr/ntv064

33. Taylor DC, Chu P, Rosen VM, et al. Budgetary impact of varenicline in smoking cessation in the United Kingdom. Value Health 2009; 12: 28-33; https://doi.org/10.1111/j.1524-4733.2008.00395.x

34. Medicines use in Italy - Osmed Report 2015. Available at http://www.aifa.gov.it/content/osmed-report 